\title{
The Formula SAE Tire Test Consortium-Tire Testing and Data Handling
}

\author{
Edward M. Kasprzak \\ University at Buffalo \\ David Gentz \\ Calspan Corp.
}

Copyright @ 2006 Society of Automotive Engineers, Inc.

\begin{abstract}
The Formula SAE Tire Test Consortium (FSAE TTC) was established to provide high quality tire data to participating FSAE teams for use in the design and setup of their racecars. Currently, data on ten different constructions of tires has been measured at Calspan's Tire Research Facility and distributed to all consortium members.
\end{abstract}

In this paper we review the history of the FSAE TTCthe inception, organization and continuing operation of this all-volunteer effort. Details of tire testing will be explored, including the many options and constraints considered while designing the tire test matrix. Finally, a review of the measured data is provided. This includes a description of all the output channels and an overview of ways in which FSAE teams can make use of the data.

\section{INTRODUCTION TO FORMULA SAE}

The Formula SAE Collegiate Design Series event was founded approximately 25 years ago. Since its relatively humble beginnings it has grown substantially in size and stature. The yearly event near Detroit, Michigan annually draws 140 teams, and in 2006 Formula SAE responded to increasing demand by adding a second US event, FSAE West in Fontana, California, with room for 70 entrants. Companion events are held yearly in England, Germany, Italy, Japan, Brazil and Australia.

These competitions are unique in two important ways. First, the competitors are all college or university students, most of them engineering students. As such, Formula SAE is intended to provide a tremendous setting for learning and a way for participating schools to impart real-world experience on their students.
Second, unlike most motorsports events, Formula SAE is more than just a performance event. It is also a design event. Industry experts volunteer their time to be design judges at FSAE competitions, reviewing each vehicle in great detail, sharing their knowledge with the students, and setting the bar on vehicle design quite high. Advancing to the Design Finals at FSAE competitions is a very prestigious accomplishment.

These two points are closely tied together. A competition that rewards both on-track performance and engineering design and student knowledge reinforces the role of Formula SAE as a learning environment. Students are expected to engineer their cars, not just build them.

This emphasis on design and understanding of the vehicle in engineering terms is a main reason why the Formula SAE Tire Test Consortium (FSAE TTC) was founded. While much of the car can be readily quantified, the tires are not easily described in engineering terms. Component stresses \& material yield strength, mass flow rates, exhaust gas temperatures, heat transfer rates, etc. can all be predicted, determined or measured with reasonable accuracy. But what about the tires? As of 2004, there was a very limited amount of engineering-quality tire data available to FSAE students.

Tires are one of the most important engineering components on the vehicle. They are the means by which the vehicle generates forces and moments for its motion. The need to understand and quantify tire performance was realized early in the history of the automobile, and the progression of tire testing techniques implemented to characterize and eventually model tire behavior is reviewed in the next section. 


\section{INTRODUCTION TO TIRE TESTING}

While the automobile was invented in the late-1800s, the study of automobile vehicle dynamics did not gain momentum until the 1920s and '30s. One of the earliest publications on tire behavior was by Broulhiet in 1925 [1] in which he established the concept of the slip angle. Until that time, the tire was largely seen as a suspension component (vertical response was studied) and as a source of power loss (rolling resistance). The force and moment characteristics of interest to modern vehicle dynamicists were only beginning to be explored.

In 1931 Becker, Fromm and Maruhn [2] produced lateral force data on a rotating drum, a side-effect of their investigation into tire shimmy. Drum testing of tire forces and moments grew throughout the 1930s, with significant contributions being made by Olley and Evans [3]. By 1939 Bull [4] was able to envision a full sixcomponent drum-type test machine.

While tire testing on drums is relatively simple, every drum-type test machine has the drawback that it presents a curved surface to the tire footprint. This curvature alters the pressure distribution in the footprint from that seen on the (nearly-flat) roadways, and thus produces somewhat different outputs than would be seen on a flat road.

On-road tire testing also began in the 1930s, with Bradley and Allen [5] publishing data measured using a motorcycle with a steerable sidecar wheel. Full sixcomponent on-road tire testing was realized in the early 1950s at Cornell Aeronautical Laboratories (CAL) [6].

The drawback to on-road testing is that it is not very repeatable. There is little control over the condition of the road surface. Pavement ages, wears, is exposed to vehicle fluids, is exposed to dirt/sand and changes characteristics as the weather changes. An indoor, flat surface test machine eliminates these concerns.

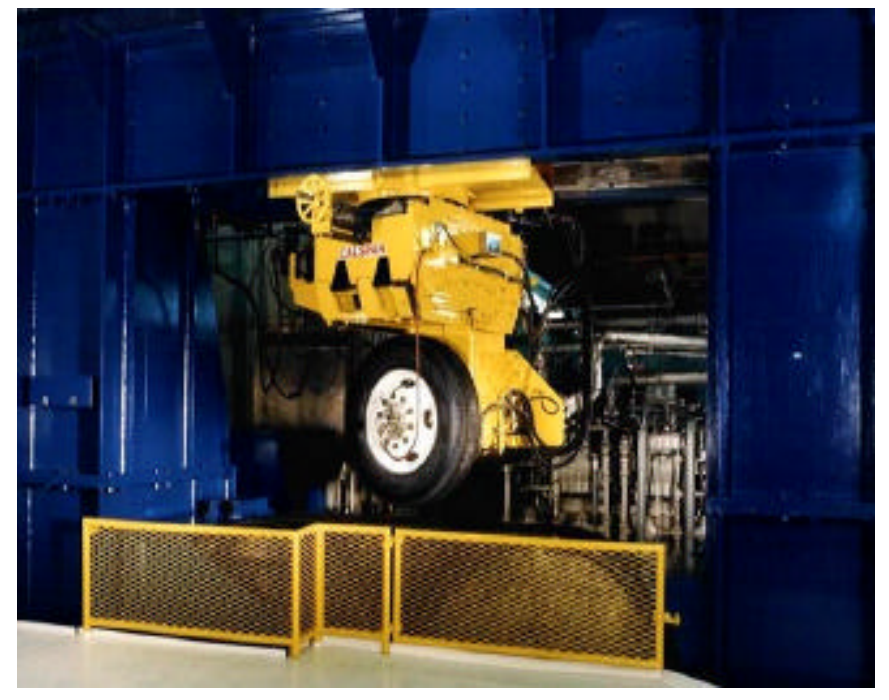

Figure 1. The main testing machine at Calspan TIRF.
A low capacity flat-belt tire test machine was developed by CAL in the 1960s. In the early 1970s, at the same time that CAL transitioned into Calspan, the experience gained with the early tire tester was used to create the main test machine in use at the Calspan Tire Research Facility (TIRF) to this day [7]. This machine is pictured in Figure 1.

This machine is the one used for the FSAE TTC tire tests. It was the world's first high speed, high load, sixcomponent flat-belt tire testing machine. It remains the most capable tire testing machine in the world, with the following capacities:

- Normal Load: Up to 12000 lb. $(53400 \mathrm{~N})$

- Normal Load rate: Up to $2000 \mathrm{lb} . / \mathrm{sec}$ (8900 $\mathrm{N} / \mathrm{sec}$.)

- Tire Vertical Position Rate: Up to 7 in./sec. (17.75 $\mathrm{cm} / \mathrm{sec}$.)

- Roadway speed: Over $200 \mathrm{mph}$

- Slip angle: \pm 30 deg., and up to 90 deg. with adapter.

- Slip angle rate: Up to $10 \mathrm{deg} / \mathrm{sec}$

- Inclination Angle: \pm 30 deg., and over +50 degrees with adapter.

- Inclination Angle rate: Up to $7 \mathrm{deg} / \mathrm{sec}$

- Inflation pressure: Can be changed/regulated during test

- Roadway surface: Belt coating can be changed to achieve different surface friction coefficients. Water can be applied at depths from 0.005 to $0.400 \mathrm{in}$. (0.125 to $10.2 \mathrm{~mm})$

- Maximum tire outside diameter: 47 in. $(119.4 \mathrm{~cm})$

- Maximum tire tread width: 24 in. $(61 \mathrm{~cm})$

- Belt width: 28 in. $(71.1 \mathrm{~cm})$

The capability at Calspan TIRF is recognized worldwide, as customers include all forms of professional auto racing (Formula 1, NASCAR, Champ Car/IRL, etc.) as well as OEM tire manufacturers and government testing in the passenger car world. Besides Calspan TIRF there are a number of tire testing machines currently in use around the world-both drum-type (which still has its uses) and flat-belt-but none can match the Calspan machine in either range of capability or history. Some other machines have been built specifically to perform transient testing, failure testing or tests on simulated offroad surfaces. The interest in tire testing continues to rise throughout the racing and passenger car industries.

\section{FOUNDING THE FSAE TTC}

During the 2004 Motorsports Engineering Conference and Exhibition Calspan TIRF manned an exhibitor's booth. Sam Pugliese and Dave Gentz spoke with many professionals and, significantly, many attending students, including those from several Formula SAE teams. Discussions about measuring FSAE tires at the Calspan facility began, and the idea for what became the FSAE Tire Test Consortium was born. 
Two things were immediately apparent. First, students had an interest in obtaining tire data for their FSAE vehicles. This was probably the most fundamental engineering gap facing the teams. A very limited set of data was openly available on one or two tire constructions, but there was generally not enough to make good engineering decisions, perform analysis or make tire models.

Second, tire testing is a very specialized kind of testing and thus is expensive- beyond all but the best-funded FSAE teams. It would be unreasonable for a single FSAE team to commission their own large-scale tire tests. The most reasonable way for students to get access to a large amount of quality tire data would be to pool resources across several FSAE teams.

By the conclusion of the 2004 SAE Motorsports Conference a small group of people had agreed to work together to see if such a group of FSAE teams could be organized. From the start, Calspan TIRF said that they would be willing to give such a group a price break in the spirit of supporting education and increasing the awareness of tire data collection and uses. The organizers of this group were:

- Denny Trimble - student at the University of Washington

- Edward M. Kasprzak - Ph.D. student at the University at Buffalo and Associate at Milliken Research Associates, Inc.

- Dr. Bob Woods - founding member of Formula SAE and professor at the University of Texas Arlington

Following the conference, Denny Trimble conducted a survey on the FSAE Forums [8] to gauge interest in forming a tire testing group. In less than a week 25 teams expressed interest, so the decision was made to establish a formal organization. By mid-December the name "Formula SAE Tire Test Consortium" was settledupon, with the three people mentioned above as coDirectors, each volunteering their time and energies to the effort.

\section{ORGANIZING THE FSAE TTC}

The three co-directors communicated with each other throughout December 2004 and early 2005 to establish the structure of the FSAE TTC. A timeline of the organization's development, from inception to the time of paper submission, is given in the Appendix.

A principal concern was the careful and transparent handling of the consortium's finances. A registration fee of $\$ 500$ per FSAE team was set, and the directors asked Doug Milliken-Vice President of Milliken Research Associates, Inc. and a Formula SAE Design Judge-to oversee the finances. He agreed to establish a dedicated bank account for the FSAE TTC and offered to maintain a spreadsheet of account transactions openly available on the internet. While not a director, Doug Milliken's involvement and input to the FSAE TTC has been significant.

Doug Milliken also offered internet space for the FSAE TTC website. This website explains the role of the consortium, the rules regarding use of the data, the plan for tire testing and the means to register \& send the registration fee. But for scheduling details, the website remains largely the same as when it was first posted [9].

Throughout early 2005 the directors worked on establishing the rules for the TTC, which were then posted on the consortium website. Tire companies were contacted, polls of interested schools were taken and the test matrix was largely defined. On 4 March 2005 the Formula SAE Tire Test Consortium opened for registration with the goal of 20 registered teams by the end of April.

Eighteen schools registered by April 30th. With $\$ 9000$ in the bank and more schools intending to register formal negotiations with Calspan began on a tire testing contract. Calspan saw three benefits to assisting the FSAE TTC. First, it was an opportunity to support engineering education. Second, it was a way to increase the awareness of tire testing and the uses of tire data in vehicle design, analysis and development. Students will carry this with them into industry upon their graduation. Finally, it would promote Calspan's test facility. Based on these factors a special contract was developed which provided the tire testing services to the FSAE TTC at approximately half the usual rate. For $\$ 15000$ three days of testing were secured.

Three days was estimated to be enough to test seven constructions based on the test matrix that was developed. Seven constructions were chosen based largely on votes from consortium members. The choice of tires and test matrix development is discussed in detail in the next section.

The scheduled test date at Calspan slipped a bit as other customers overran their scheduled time and machine maintenance needed to be performed. This was expected, and despite the realities of running such a test facility Calspan manages to keep fairly closely to their scheduled test days. The delay proved to be beneficial, too, as the $10 \mathrm{in} .(25.4 \mathrm{~cm})$ rims ordered weeks before the scheduled test were late in arriving. After much pestering (and anxiety on the part of the lead author) the company finally shipped them-they arrived the morning of the first test day!

The day before Round One of testing began also saw the 31st member join the FSAE TTC. This meant that $\$ 15500$ was in the bank, and the $\$ 15000$ owed to Calspan for the tests would not put the consortium in the red.

As discussed in the next section, Round One ultimately saw five constructions tested over two days, leaving a 
third day on the contract to be applied toward Round Two. The tests themselves went relatively smoothly. Students from several FSAE teams observed the tests, interacted with the Calspan engineers and technicians, and participated by taking pre- and post-test measurements of tread depth, tire weights and asking a number of good questions.

\section{DEVELOPMENT OF THE TEST MATRIX}

Considerable discussion went into the development of the tire test matrix. This discussion took place among the consortium directors and Dave Gentz at Calspan. Input from consortium members was requested and considered to help define test ranges and operating variables of interest. Additional input from Doug Milliken and The Goodyear Tire \& Rubber Company was also applied to the final test plan.

Decisions were made based on factors that can be grouped into the following general categories:

- Operating conditions seen on FSAE vehicles

- Relevant parameters

- Calspan TIRF machine capabilities \& setup

- Budget/time constraints

- Tire popularity and availability

We now look at each of these categories individually.

\section{OPERATING CONDITIONS}

Most FSAE vehicles weigh somewhere between 400 and $700 \mathrm{lb}$. (1780 to $3110 \mathrm{~N})$. Some teams employ devices to create aerodynamic downforce, which could add up to $200 \mathrm{lb}$. $(890 \mathrm{~N})$ at high speed to the total wheel loads. Considering the static weight distribution, aerodynamic distribution and load transfers experienced during acceleration, braking \& cornering, the highest single wheel loads seen on FSAE vehicles were estimated to be around $400 \mathrm{lb}$. $(1780 \mathrm{~N})$. The FSAE TTC decided to test up to $450 \mathrm{lb}$. $(2000 \mathrm{~N})$ normal load.

An informal survey of FSAE teams indicated that they were using tire pressures in the 10-15 psi (69 to 103 $\mathrm{kPa}$ ) range. Consultation with Goodyear indicated that 12 psi $(83 \mathrm{kPa})$ was suggested for their tires. We decided to test pressures ranging from 8 to $16 \mathrm{psi}$ (55 to $110 \mathrm{kPa}$ ). This pressure was regulated during the test through Calspan's rotary union which connects the tire's valve stem to a pressure valve. If left unregulated, as the air inside the tire increases in temperature it would also increase the inflation pressure. Regulating the tire pressure reduces the variation in tire data caused by these unwanted pressure changes.

The FSAE teams indicated that most teams run little static camber, and with relatively small suspension deflections (less than 3 in. or $7.6 \mathrm{~cm}$ total travel) the camber gain on these vehicles is not significant. Again, Goodyear advised to stay below a few degrees of inclination on their tires. The consortium directors chose to test inclination angles up to $4 \mathrm{deg}$. Tire slip angles and slip ratios were selected to ensure that the peaks of the lateral and longitudinal force curves were surpassed.

Roadway speed was chosen based on two factors. First, since tires exhibit some variation in performance with velocity, especially with respect to vertical spring rate and loaded radius, the test speed needed to be in a range typically seen on the vehicle. Second, and more significantly, test speed is an important way to control tire temperatures. Tire temperature is not able to be directly controlled on the testing machine-it is a function of the test design. In general, as roadway speed increases on the test machine so does tire temperature.

Another factor affecting temperature in the tire is the slip angle sweep rate (and the slip ratio sweep rate for drive/brake tests). Slower sweeps take more time to complete, during which the tire generates and stores more heat. A sweep rate of $4 \mathrm{deg} . / \mathrm{sec}$. was used for the consortium tire tests. Additionally, dwells-a period of time where the tire is running without slip angle-are placed between each consecutive sweep to give the tire a chance to cool. Longer dwells keep tire temperatures down, while shorter dwells result in higher tire temperatures.

Calspan also has heaters to raise both the test room's ambient temperature and the temperature of the roadway belt. The latter is important as the air bearing supporting the roadway and tire load tends to extract heat from the belt. Belt heaters were run during the tests to counteract this effect.

A test speed of $25 \mathrm{mph}$ (40.2 kph) was selected as a typical skidpad speed at FSAE competition which also gave reasonable test temperatures. Post-test pyrometer readings ranged between 110 and $150^{\circ} \mathrm{F}\left(43\right.$ to $66^{\circ} \mathrm{C}$ ), ranges which FSAE students attending the tests said were roughly what they were seeing on their vehicles.

\section{RELEVANT PARAMETERS}

The previous section mentioned several parameters which were varied in the test: normal load, slip angle, inclination angle, slip ratio and inflation pressure. It also mentioned roadway speed, which was held constant.

There are several other parameters which were not tested, based on limited time and budget. Perhaps the most significant of these concerns the wheels used in the tests. All 13 in. $(33 \mathrm{~cm})$ tires were tested on the same 6 in. wide rims, borrowed from the local University at Buffalo FSAE team. Using a single rim design eliminated a variable from the test matrix. This saved time and money, but it also prevented studying the effect of different rims on tire performance. Similarly, all $10 \mathrm{in} .(25.4 \mathrm{~cm})$ tires were run on the same 6 in. $(15.2 \mathrm{~cm})$ wide rim, purchased specifically by the consortium for these tests. 
Rim width can have an effect on tire performance, as it changes the angle at which the sidewall connects the rim with the tread. Wheel compliance is also a reality, with stiffer wheels having less compliance. Tire designers usually prefer very stiff wheels so that the wheel deflection does not have a significant effect as tire designs are compared. Race and vehicle OE users usually like the tire/wheel data collected using their wheel of choice. Either way it is a minor player for the majority of tire testing.

Another "parameter" that is very important in tire testing is the technique used to warm-up and condition a new tire before implementing the test matrix. A brand new "sticker" tire does not have the same force and moment characteristics as a tire that has seen some use. The initial break-in of a new tire serves to bring the tire up to temperature as well as work the tire such that the internal molecular crosslinks and various plies rearrange themselves into their "used" condition. This break-in is the final major step in the curing of the tire, and it needs to be completed before data relevant to the long-term use of the tire can be collected.

Break-in consisted of running the tire at alternating slip angles of \pm 2 deg. and alternating inclination angles of \pm 2 deg. for two minutes on the roadway at $25 \mathrm{mph}(40.2$ $\mathrm{kph})$. This was followed by two conditioning slip angle sweeps to large positive and negative slip angle, each at a midrange load. After these, the actual test was implemented.

Tire wear, which can be a significant parameter, was not studied. Very reasonable tire wear appeared during the tests, so we were not concerned. Measuring the effect of tire wear through dedicated testing would require a substantial increase in test matrix size and, thus, cost.

Besides the slip angle sweeps there are a number of other tests that can be conducted at Calspan TIRF. Spring rate tests were performed at several points during the test sequence to monitor how the vertical spring rate varies with test technique and tire use. Both static (non-rolling) and dynamic (rolling) tests were performed.

Tests for tire conicity and plysteer are also common in industry, but these were not run by the consortium. Conicity is the tendency of a tire to produce lateral force at zero slip angle, like a styrofoam cup that always turns in one direction. Plysteer is the tendency of a tire to produce lateral force at zero slip angle similar to the threads on a screw-reverse the direction of rotation and the lateral force at zero slip angle also reverses direction. There are also specific tests for rolling resistance, wear, wet testing, axle rise versus velocity, disk braking and many more which were not performed during the FSAE TTC tests.
Despite the range of tire testing capability at Calspan TIRF, the small FSAE tires presented a challenge to the facility's engineers.

The first concern was whether or not the head of the machine, the part on which the wheel is mounted, had enough travel to provide the desired wheel loads. The machine contains a mechanical hard-stop which, in the event of a serious machine failure, prevents the head of the machine from falling onto/through the belt and air bearing. Preliminary checks showed that the 13 in. (33 $\mathrm{cm})$ tires had a sufficiently large radius. The head of the machine was near the end of its travel, but even at high loads and high lateral forces when the loaded radius of the tire is the smallest it was still within its operating range.

For the 10 in. $(25.4 \mathrm{~cm})$ tires, however, an adapter plate was mounted on the head to mount the wheel below the head and allow sufficient travel above the hard-stop. This plate can be seen in Figure 2-note how the spin axis of the wheel is below the main axis of the head. As a consequence, since drive/brake torques could not be passed through the adapter plate the $10 \mathrm{in} .(25.4 \mathrm{~cm})$ tires would be restricted to free rolling tests only.

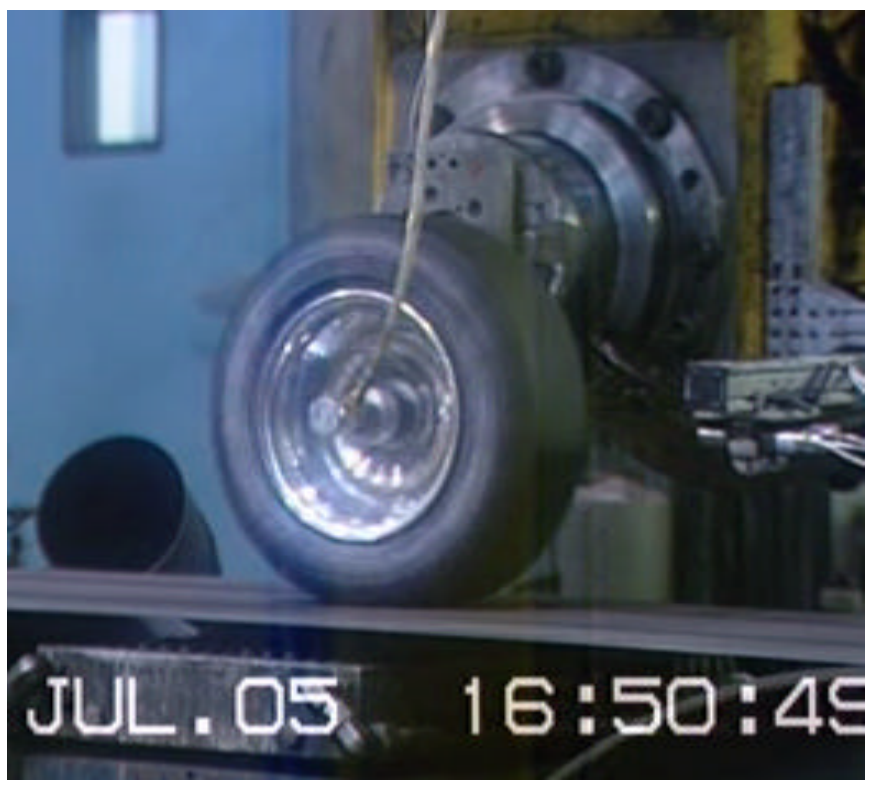

Figure 2. A 10 in. $(25.4 \mathrm{~cm})$ tire on the adapter plate.

Additionally, since the machine was operating near its travel limits only positive inclination angles were to be tested. At TIRF, positive inclination effectively raises the machine head and negative inclination decreases it. Since the tires are not built with any intentional bias toward a single direction the restriction to a single direction of inclination angle was not seen as a problem. Slip angles were swept in both left and right turn 
directions, so data on both aiding and defeating camber was obtained.

The three scheduled days of testing at Calspan included not only time running the machine, but also time settingup the machine. As with any test, the first step is to reconfigure the machine from the previous customer's test. This can include a variety of different tasks, including switching from a wet to dry test setup, replacing the main straingauge balance (Calspan has a high load and a low load straingauge balance), replacing/repairing the belt and fitting the correct bolt pattern for the next customer's wheels, among others.

When the machine is fully reassembled a series of short check tests are made to make sure the machine is performing properly. A full calibration is not performed-those are done periodically and take several days to complete.

The same set of checks are performed after fitting or removing the adapter plate, and reconfiguring the machine for drive/brake testing. The latter involves manually connecting the driveshaft to the transmission. This is left disconnected during free rolling tests.

Once the machine is in the correct configuration and has passed all the checks tire testing commences, and typically goes smoothly, barring the occasional part failure. The small FSAE tires did not stress the machine very hard so no failures were expected, and none occurred.

The last item of concern is having mounted tires prepared to go on the machine. Calspan has several tire mounting machines and are able to mount and dismount tires while testing is taking place. The consortium used three $13 \mathrm{in} .(33 \mathrm{~cm})$ rims and two 10 in. $(25.4 \mathrm{~cm})$ rims during testing, which meant that we did not have to wait for mounting/dismounting. A fourth 13 in. $(33 \mathrm{~cm})$ rim was available, but pre-test checks showed it to be out-of-round and unacceptable for tire testing.

Placing and removing tires from the machine is fairly straightforward. The head sits at chest level, which means the tire must be raised about $4 \mathrm{ft}$. $(1.2 \mathrm{~m})$ off the ground to be placed on the studs. Once secured, the rotary union is attached so that pressure can be regulated. While not used in the FSAE TTC tests, Calspan also has the ability to measure the contained air temperature during the test if a specially modified rim is used. When used, reattaching the probe becomes an extra step when placing a tire on the machine.

\section{BUDGET AND TIME CONSTRAINTS}

When finalizing plans for the first round of tests in June 2005, member registrations had accumulated nearly $\$ 15000$ in the FSAE TTC account. As mentioned before, this would allow three days of testing at Calspan based on the special (approximately half price) contract negotiated between Calspan and the consortium.

These three days, two shifts per day, would include the machine setup mentioned above, along with actual tire testing. As the test plan came together it was estimated that seven constructions of tires could be tested in a three day period. There were several unknowns, the biggest of which was tire wear. Somewhat conservative tests were planned, and time was allowed to swap tires during each test. Swapping tires on the machine takes about 10 minutes and the entire warm-up and conditioning procedure needs to be rerun each time a new tire is placed on the machine-items which add-up quickly when testing a few dozen tires.

\section{TIRE POPULARITY AND AVAILABILITY}

As mentioned previously, the registration form allowed each FSAE team to vote for which tires they wanted to see tested. The consortium directors took this information into consideration when choosing tires to test. The final decision for Round One of testing in July 2005 settled on the following tires:

- Hoosier 20x6-13 R25A

- Hoosier 20x7-13 R25A

- Hoosier 18x6-10 R25A

- Goodyear 20x6.5-13 R065

- Goodyear 20x7-13 R065

- Goodyear 18x6.5-10 R065

- Avon: 20x6.2-13 A45

Of the tires listed, the 10 in. $(25.4 \mathrm{~cm})$ Goodyear was not available from Goodyear, and another batch was not scheduled for production until after the tests were to be completed. Negotiations with Avon were unsuccessful, so they were not available for testing either. That left five compounds for testing. The reduced number of tires and (as it turned-out) better-than-expected wear meant that only two days of testing were used in Round One, leaving a third day remaining on the contract.

For Round Two in February 2006, increased consortium membership provided sufficient finances for a fourth day to be negotiated on the contract. This allowed two days of testing and five more constructions in Round 2:

- Goodyear 18x6.5-10

- Hoosier 20.5x7.0-13

- Hoosier 20.5x6.0-13

- Avon 6.2/20.0-13

- Avon 7.2/20.0-13

This time the 10 in. $(25.4 \mathrm{~cm})$ Goodyear was available. As with Round One, all Goodyear and Hoosier tires were donated by the respective companies, while the Avons were purchased. In return, Goodyear and Hoosier were given a copy of the same data distributed to all consortium members. 
As of September 2006 a third round of testing is being discussed by the consortium directors. Additional tire constructions (or updates of existing constructions) could be tested, including other manufacturers (such as Michelin) which appear in the FSAE series.

\section{IMPLEMENTING THE TEST MATRIX}

After much discussion the above considerations and constraints were weighed and a test matrix was developed. Each tire construction was subjected to three different tests on the machine. Two were free rolling and the other was a drive/brake test. A description of each test follows.

In general, for lateral force tests, a series of slip angle sweeps were performed during which all other variables were held constant. All combinations of the selected discrete load and inclination values received their own sweep. Thus, for a case with 5 discrete inclination angles and 5 discrete loads a total of 25 slip angle sweeps were performed.

\section{TEST 1: FREE ROLLING, SINGLE PRESSURE}

In the first free rolling test, a roadway speed of $25 \mathrm{mph}$ $(40.2 \mathrm{kph})$ was used and the pressure was regulated to $12 \mathrm{psi}(83 \mathrm{kPa})$. The test sequence was as follows:

- Static (non-rolling) spring rate test on brand new tire

- Dynamic (rolling) spring rate test on brand new tire. Speed at $25 \mathrm{mph}(40.2 \mathrm{kph})$ for the rest of the test.

- Tire Break-in. Oscillation in slip angle and inclination angle to $\pm 2 \mathrm{deg}$. for approximately 2 minutes.

- Conditioning Sweeps. Two steers to \pm 12 deg. slip angles at $250 \mathrm{lb} .(1112 \mathrm{~N})$ load

- Dynamic spring rate test on tire after break-in.

- Slip angle sweeps to \pm 12 deg. at all combinations of loads and inclination angles.

- Inclination angles: 0, 1, 2, 3, 4 deg.

- Loads: $350,250,150,50,450 \mathrm{lb}$.

$(1557,1112,667,222,2002 \mathrm{~N})$

- Post-test dynamic spring rate (worn tire).

In total this test contained four spring rate tests, 27 slip angle sweeps and a three minute break-in cycle.

\section{TEST 2: FREE ROLLING, MULTIPLE PRESSURES}

The second free rolling test was conducted to investigate the effects of inflation pressure on tire characteristics. As with the first free rolling test, a roadway speed of $25 \mathrm{mph}$ (40.2 kph) was used. This time, however, the inclination angle was held fixed at 0 deg. The test sequence was as follows:

- Static (non-rolling) spring rate test on brand new tire

- Dynamic (rolling) spring rate test on brand new tire. Speed at $25 \mathrm{mph}(40.2 \mathrm{kph})$ for the rest of the test.
- Tire Break-in. Oscillation in slip angle and inclination angle to $\pm 2 \mathrm{deg}$. for approximately 2 minutes.

- Conditioning Sweeps. Two steers to \pm 12 deg. slip angles at $250 \mathrm{lb} .(1112 \mathrm{~N})$ load

- Dynamic spring rate test on tire after break-in.

- Slip angle sweeps to \pm 12 deg. at various loads and pressures.

- Pressures: 8, 10, 12, 14, 16 psi.

$(55,69,83,97,110 \mathrm{kPa})$

- Loads: 350, $150 \mathrm{lb} .(1557,667 \mathrm{~N})$

- Dynamic spring rate test for every pressure performed between slip angle sweeps

- Post-test dynamic spring rate (worn tire).

This test contained nine spring rate tests, 12 slip angle sweeps and a two minute break-in cycle.

\section{TEST 3: DRIVE/BRAKE TESTS}

The drive/brake tests were conducted to collect longitudinal force data on the tires. As with the free rolling test, a roadway speed of $25 \mathrm{mph}$ (40.2 kph) was used. The sweep conditions are a combination of the first two tests. In the first part the pressure is held fixed at $12 \mathrm{psi}(83 \mathrm{kPa})$ while a range of inclination angles are tested. In the second part of the test several pressures are tested while the inclination angle was held fixed at 0 deg. The test sequence was as follows:

- Tire Break-in. Oscillation in slip angle and inclination angle for appx. 2 minutes.

- Conditioning Sweeps (slip angle). Two steers to \pm 12 deg. slip angles at $250 \mathrm{lb}$. (1112 N) load.

- Conditioning Sweeps (slip ratio) Two test SR cycles at mid load to properly heat compound.

- Slip ratio sweeps to \pm 0.20 at various loads, 12 psi (83 kPa), 0 slip angle

- Loads: 350, 250, 150, lb.

- Inclination Angles: 0, 2, 4 deg

- Slip ratio sweeps at various loads, 8 psi, 0 slip angle

- Loads: 350, 250, 150, Ib. (1557, 1112, $667 \mathrm{~N})$

- Inclination Angles: 0, 2, 4 deg

- Slip ratio sweep at $250 \mathrm{lb}$. (1112 N) to very large \pm slip ratio (almost locked, spinning)

This test contained no spring rate tests, 18 slip ratio sweeps, two slip angle sweeps and a two minute breakin cycle.

All tests were videotaped, and the videos were provided to consortium members along with the tire data. Photographs of each tire were also taken after the test was completed as a way to show tire wear. Immediately following each test pyrometer readings were taken across the tread of the tire. 


\section{MEASURED OUTPUTS \& DATA ANALYSIS}

During each test, the following data channels were recorded at $0.02 \mathrm{sec}$. intervals:

- Elapsed Time, sec

- Roadway Velocity, mph or kph

- Tire Rotational Velocity, rpm

- Slip Angle, deg

- Inclination Angle, deg

- Loaded Radius, in or $\mathrm{cm}$

- Effective Radius, in or $\mathrm{cm}$

- Inflation Pressure, psi or kPa

- Longitudinal Force, Ib. or $\mathrm{N}$

- Lateral Force, lb. or N

- Normal Load, lb. or N

- Overturning Moment, lb.-ft. or N-m

- Aligning Torque, lb.-ft. or N-m

- Normalized Longitudinal Force, unitless

- Normalized Lateral Force, unitless

- Road Surface Temperature, ${ }^{\circ} \mathrm{F}$ or ${ }^{\circ} \mathrm{C}$

- Inside Tire Surface Temperature, ${ }^{\circ} \mathrm{F}$ or ${ }^{\circ} \mathrm{C}$

- Center Tire Surface Temperature, ${ }^{\circ} \mathrm{F}$ or ${ }^{\circ} \mathrm{C}$

- Outside Tire Surface Temperature, ${ }^{\circ} \mathrm{F}$ or ${ }^{\circ} \mathrm{C}$

- Ambient Temperature, ${ }^{\circ} \mathrm{F}$ or ${ }^{\circ} \mathrm{C}$

- Slip Ratio, unitless

All forces and moments follow the SAE tire axis system as defined in SAE J2047 [10] as shown in Figure 3.

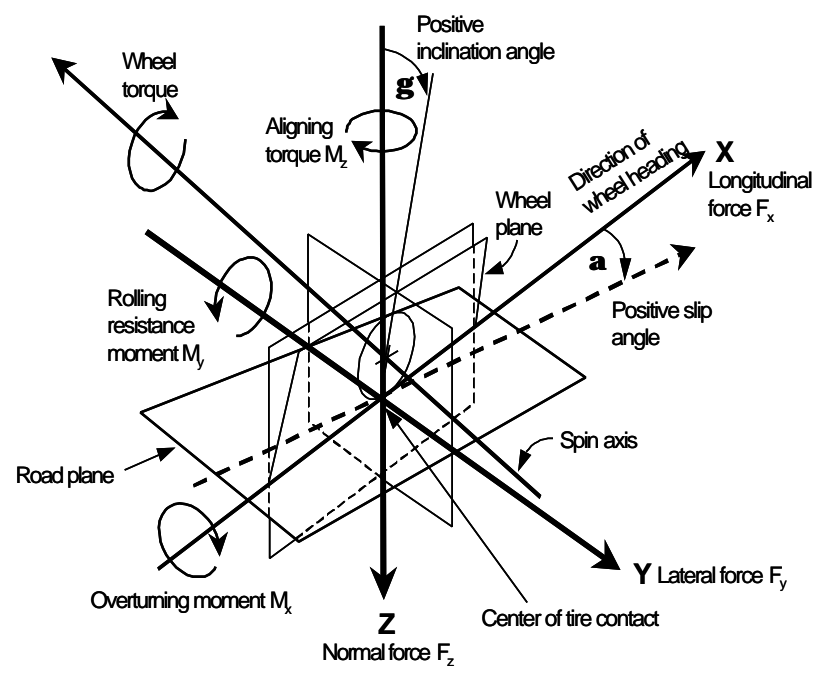

Figure 3: The SAE Tire Axis System

The purpose of this paper is not to analyze and make conclusions on the tire data collected in the two rounds of testing - that is a task for the students! It is, however, relevant to show some of the data in graphical form to discuss certain aspects of the tests.
Typical lateral force versus slip angle raw data is shown in Figure 4. This plot contains 5 loads and 5 inclination angles worth of data, which can be sub-divided into 25 individual curves.

The raw data contains several features which are not seen in textbook descriptions of tire performance. First, as expected with any real-world measurement there is some amount of noise in the data. Second, there is temperature variation in the data, as seen in Figure 5. As any tire is steered the surface temperature increases - the slip angle to sweep from zero to a large slip angle often produces somewhat lower lateral force than the return sweep to zero because of the higher temperature of the return sweep. Note that these are surface temperatures, taken by infrared sensors mounted in front of the tire $(3 / 4$ rotation past the footprint). Pyrometer readings were also taken at the conclusion of each test for comparison.

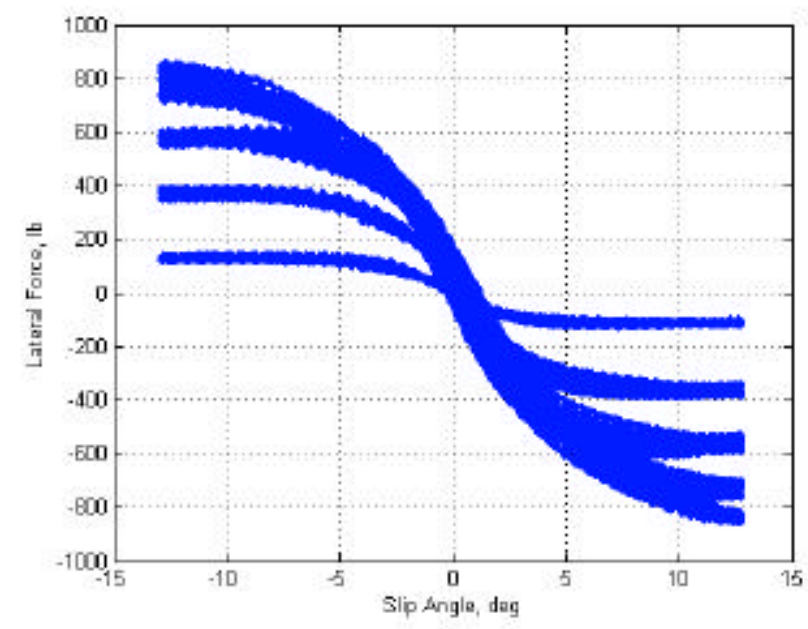

Figure 4. Typical lateral force vs. slip angle raw data

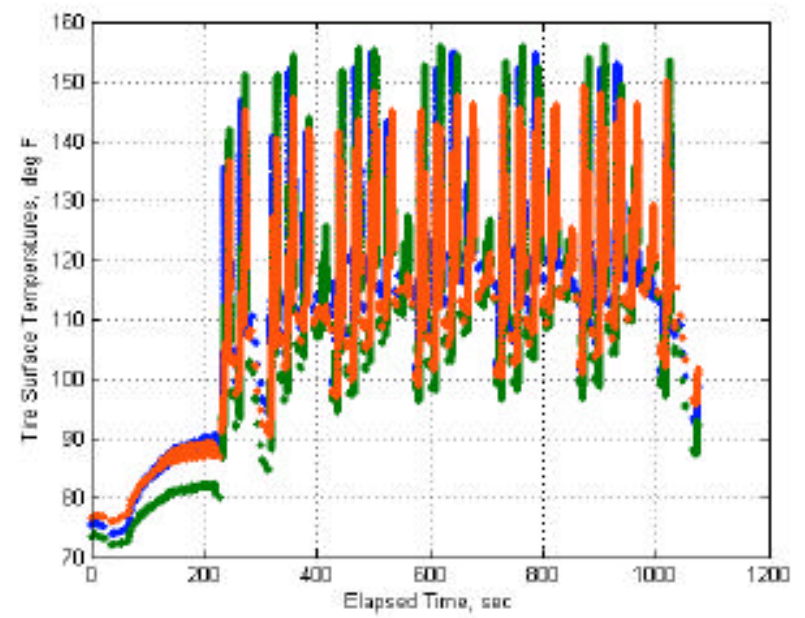

Figure 5. Sample inner, center and outer tread temperatures 


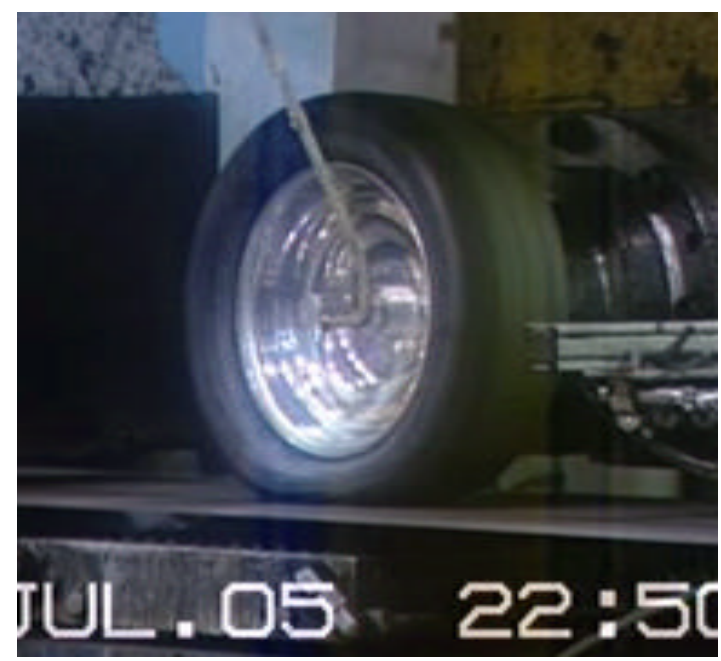

Figure 6 Sidewall deflection while cornering

As a tire produces lateral force, the sidewalls deflect laterally, resulting in a loss of loaded radius. To hold constant load, the head of the test machine must raise and lower as the tire is steered. A photo of the sidewall deflection is shown in Figure 6. A plot of loaded radius versus slip angle is shown in Figure 7 . The curves in this graph form five groups, each one corresponding to one normal load. As normal load increases the tire gets shorter, and as the tire is steered the tire also gets shorter. This is most noticeable at very high loads.

A careful look at Figure 7 shows that there is some leftright asymmetry. This is due to a phase lag in the test machine's ability to maintain normal load. These small, low spring rate FSAE tires proved to be a challenge for the test machine. The effect of the normal load variation about the target is also present in the data of Figure 4.

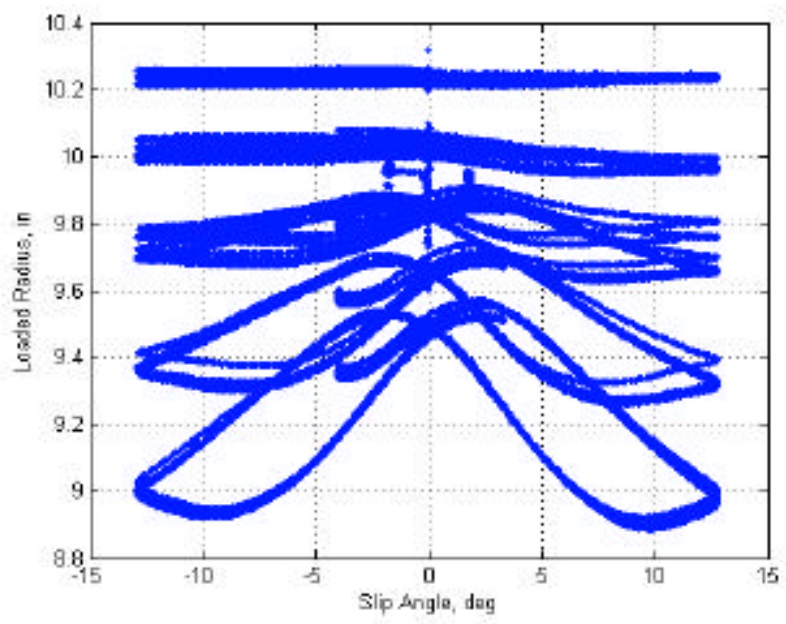

Figure 7. Loaded radius vs. slip angle
The tests contained four dedicated spring rate tests. Sample spring rates for one construction were as follows:

- Pre-test, non-rolling: $708 \mathrm{lb} /$ /in $(1239 \mathrm{~N} / \mathrm{cm})$

- Pre-test, rolling: $797 \mathrm{lb} . / \mathrm{in}(1395 \mathrm{~N} / \mathrm{cm})$

- Post-warmup, rolling: $737 \mathrm{lb} . / \mathrm{in}(1290 \mathrm{~N} / \mathrm{cm})$

- Post-test, rolling: $705 \mathrm{lb} . / \mathrm{in} .(1234 \mathrm{~N} / \mathrm{cm})$

This trend was seen in all the tires tested. The brand new tire's spring rate was much lower when measured non-rolling when compared with rolling at $25 \mathrm{mph}(40.2$ $\mathrm{kph})$. The initial warmup and conditioning sweepsperformed to break-in the tire-reduce the tire's spring rate significantly. The post-test spring rate shows a further reduction, although not as much as occurred during break-in. Somewhat surprisingly, the non-rolling spring rate of the new tire was typically very close to the rolling, worn tire's spring rate. This indicates that static testing of new tires could provide meaningful spring rate data on rolling, worn FSAE tires.

Figures 8 and 9 show typical longitudinal force and aligning torque plots, respectively. The longitudinal force plot contains data at three loads, with each load containing three inclination angles. The aligning torque plot contains 25 slip angle sweeps grouped by 5 loads each containing 5 inclination angles-just as in Figure 4.

As the tests were being run each set of data was reviewed in the control room at Calspan. Calspan has tools to plot their raw data so that checks on the test can be performed. These checks compare machine performance to the test matrix to determine that test conditions were met. Outputs are reviewed for anomalies and to determine if the tire behavior characteristics or ranges of interest were produced by the specified test conditions. Sensor errors, excessive noise, tire problems (for example, excessive wear, out of balance), machine problems, etc. can all be spotted by a quick review of the data before the next test is run.

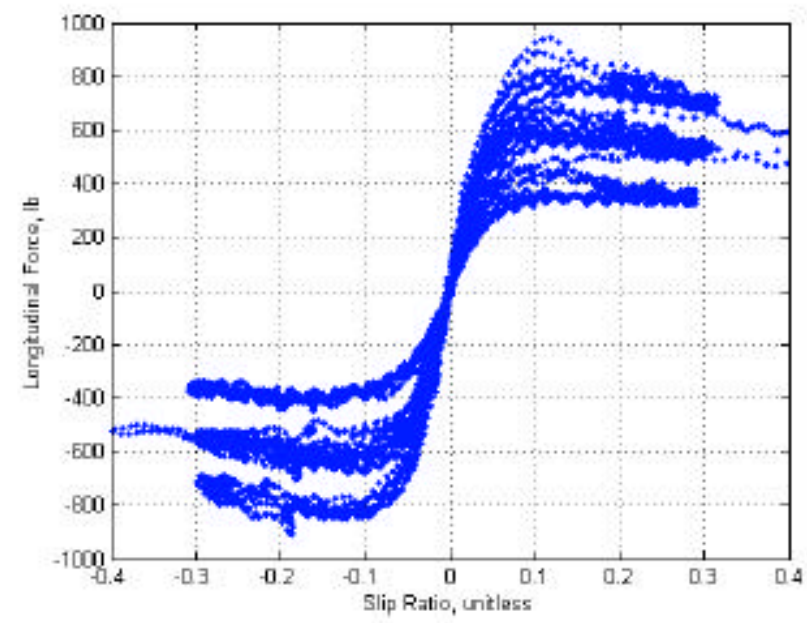

Figure 8. Typical Longitudinal Force vs. Slip Ratio data 


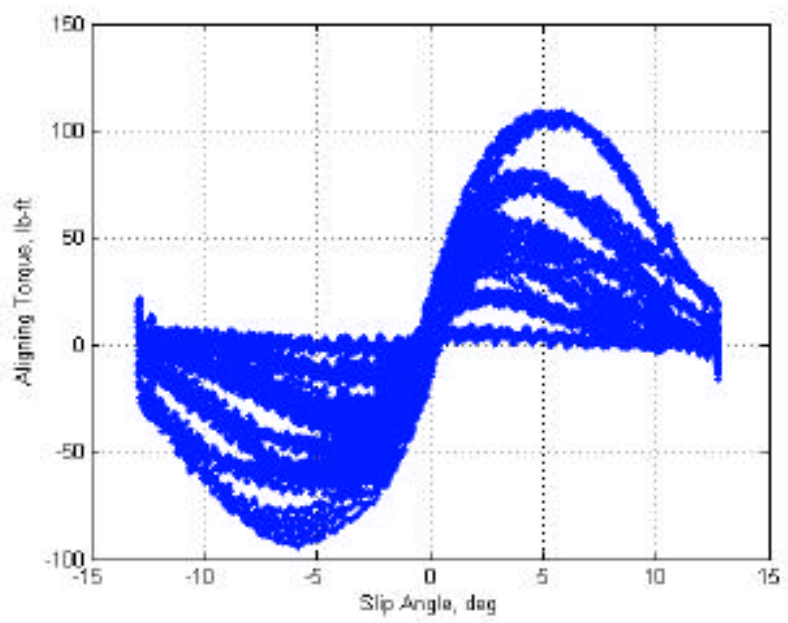

Figure 9. Typical Aligning Torque vs. Slip Angle data.

These are just a few plots which provide a flavor of the raw data produced during the FSAE TTC tire tests. Many, many more plots could be made, and students will have plenty of raw data to analyze, discuss, ask questions and argue about for years to come.

\section{DELIVERABLES}

At the conclusion of each round of tests each consortium member was sent a DVD containing the following:

- 21-channel raw data from the tire tests

- ASCII format, USCS units

- ASCIl format, metric units

- ASCIl format, mixed units

- Matlab format, USCS units

- MRA Nondimensional Tire Model of each construction

- SES Pacejka 96 model of each construction

- Video of each test

- Photographs of each tire after test

- Summary tables for each test provided by Calspan

From there, it's up to the FSAE students to make good use of the data. It is the hope of the FSAE TTC that we will see the data used in interesting ways at the various Formula SAE competitions. We will also be watching for papers to be written which make use of the data. The FSAE TTC allows the data provided to each FSAE team to be used not only within the team but for any other academic purpose within that team's college or university. In this way the tire data is available for research projects beyond those related to the FSAE teams.

\section{FSAE TTC: ROUND TWO AND BEYOND}

After the first round of testing was concluded and the data was shipped to consortium members, plans for a second round of testing commenced. Discussions among the consortium directors led to the following decisions.

An extension of the contract with Calspan was sought to allow two days of testing instead of the single day remaining on the contract. This allowed five more tire constructions to be tested as per the test matrix of Round One. No changes to the test matrix were planned. This allowed direct comparison between the tests in Round One and the tests in Round Two.

The directors selected the next five most popular tires for testing, and Goodyear and Hoosier once again promptly agreed to donate tires. Avon tires were purchased and the 10 in. $(25.4 \mathrm{~cm})$ and 13 in. $(33 \mathrm{~cm})$ rims from Round One testing were again shipped to Calspan. The second round of testing took place in February 2006, with the final DVD of data, video and tire models shipped in March 2006.

Registration for the FSAE Tire Test Consortium remains open. As of September 2006 over 65 registrants count themselves as members. Each new member receives the DVD from Round One and Round Two.

The continuing increase in membership means that the consortium bank account contains sufficient funds for a third round of testing. The leadership has discussed this possibility. There are additional tire constructions of interest, including tires from manufacturers not yet tested. A test of FSAE rain tires would be very interesting. Other variables such as rim width could also be studied. As time goes on the consortium leadership will decide when and how to pursue a third round of testing.

When the time comes to disband the FSAE Tire Test Consortium, any funds remaining in the account are planned to be put back into the FSAE competitions. Funds will be used to sponsor awards relating to the use of the tire data. There are no plans to disband the consortium at this time.

\section{CONCLUSION}

The Formula SAE Tire Test consortium was established to make a large amount of high quality tire data available to Formula SAE teams and their respective schools. This project has been highly successful, with over 65 teams registering and 10 tire constructions having been tested at Calspan's Tire Research Facility to date. Organization of the consortium has been a large, all-volunteer effort as described in this paper. The resulting data is the same type and quality as measured by professional racing teams and passenger car OEM's at Calspan's facility. Students are now 
tasked with making good use of this data on their Formula SAE vehicles and in their university research.

\section{ACKNOWLEDGMENTS}

The authors would like to thank all those who have contributed to the FSAE Tire Test Consortium: Dr. Bob Woods, Denny Trimble, Edward Kasprzak, Sam Pugliese (Calspan), Dave Gentz (Calspan), Calspan Corporation, Doug Milliken (MRA), Milliken Research Associates, Inc., Stackpole Engineering Services, Inc., Frisby's Performance Tire, The Goodyear Tire and Rubber Company and Hoosier Racing Tire. We would also like to thank the FSAE teams who have joined the consortium for their participation in this project.

\section{REFERENCES}

1. Broulheit, G., "The Suspension and the Automobile Steering Mechanism: Shimmy and Tramp", Société des Ingénieurs Civils de France, bulletin 78, 1925.

2. Becker, G., H. Fromm and H. Maruhn, "Vibrations of the Steering Systems of Automobiles", Krayn, Berlin, 1931.

3. Evans, R.D, "Properties of Tires Affecting Riding, Steering and Handling", JSAE, February 1935.

4. Bull, W. A., "Tire Behavior in Steering", Journal of Society of Automotive Engineering, vol. 45, no. 2, p. 344, 1939.

5. Bradley, J. and R. F. Allen, "Factors Affecting the Behaviour of Rubber-Tyred Wheels on Road Surfaces", 1930-31 Proc. Inst. Automobile Eng., vol. 25, p. 63, 1930.

6. Close, W. and C. Muzzey, "A Device for Measuring Mechanical Characteristics of Tyres on the Road", The Insitution of Mechanical Engineers, London, 1956.

7. Bird, K.D. and J. F. Martin, "The Calspan Tire Research Facility: Design, Development and Initial Test Results", SAE Paper No. 730582, presented at the SAE Automobile Engineering Meeting, Detroit, Michigan, May 14-18, 1973.

8. Formula SAE Forums: www.fsae.com

9. FSAE Tire Test Consortium website: www.millikenresearch.com/fsaettc.html

10. Tire Performance Technology, SAE J2047, Technical Standard, Society of Automotive Engineers, Warrendale, PA, 1998.

\section{CONTACTS}

Edward M. Kasprzak

Ph.D. candidate, University at Buffalo SUNY

Associate, Milliken Research Associates, Inc.

(716) 471-1742

kasprzak@eng.buffalo.edu

David Gentz

Principal Mechanical Engineer

Calspan Corporation Tire Research Facility

(716) 631-6857

david.gentz@calspan.com

\section{APPENDIX}

\section{FSAE TTC Timeline of Events}

\section{December 2004}

- Initial idea hatched at 2004 SAE Motorsports Engineering Conference, Dearborn, MI.

- Informal survey taken to gauge FSAE team interest

- FSAE TTC leadership organized

January 2005

- Doug Milliken on-board to oversee finances

- Preliminary discussions regarding the test matrix with FSAE teams and Calspan

- Contact tire suppliers

February 2005

- Development of website with consortium rules, regulations and registration form

- Continued planning of tire test matrix

March 2005

- FSAE TTC open for registration

April 2005

- 18 registrants by April 30th, when voting for Round One tire constructions ceased

May 2005

- Formal contract discussions with Calspan

- Tentative test date established in mid-June

- Finalized list of tires for Round One

- Finalized test matrix

June 2005

- Test moved to mid-July

- Shipment of tires and wheels to Calspan

- Discussions with FSAE students planning to attend the tests

July 2005

- Membership reaches 30 members

- Round One of testing at Calspan in late-July

- Tire models provided by Stackpole Engineering Services and Milliken Research Associates

August 2005

- Assembly of DVD for shipment to consortium members

- Delivery of Round One data to consortium members

September \& October 2005

- Continuing to process registrations, ship DVDs and respond to member questions

- Promote FSAE TTC 


\section{November 2005}

- Begin plans for Round Two of testing

- Decide on tire constructions to be tested

- Begin discussions with Calspan on contract extension

- Tentative test date for late-January

December 2005

- Agree not to modify test matrix

- 46 registrants at year's end

January 2006

- Obtain tires for Round Two tests

- Test date moved to mid-February

- Discussions with students who will attend Round Two testing

February 2006

- Round Two of testing

- Tire models provided by Stackpole Engineering Services and Milliken Research Associates

March 2006

- Round Two DVDs shipped to consortium members

April \& May 2006

- Continuing to process registrations, ship DVDs and respond to member questions

June 2006

- Denny Trimble departs consortium leadership after his graduation from $U$. Washington

- Informal discussions among directors about a third round of Calspan testing

September 2006

- Membership surpasses 65 members.

- Serious discussions among leadership about a third round of testing, possibly taking place in 2007. 